\title{
10
}

\section{Creeping Plants and Winding Belts: Cognition, Kinship, and Metaphor}

\author{
Bojka Milicic
}

\section{Introduction}

Hal Scheffler's work has been fundamental in illuminating studies of human kinship and his perspective on kin terms lends itself to a cognitive approach. There is a growing body of research (e.g. Leaf and Read 2012) showing that the study of kinship has a great potential for gaining insight into cognitive processes. Thus studying metaphors that describe concepts from the domain of kinship are salient for the study of human cognition.

Advocates of culturalist or performative persuasion argue that native theories about biological procreation are purely culturally constructed and are only metaphors of social relations, while sociobiologists and evolutionary ecologists would have it the other way around: for the former, Darwinian fitness is just a metaphor of immortality; for the latter, immortality is just a metaphor of Darwinian fitness. Thus Marshall Sahlins, a culturalist, argues: 'Whereas it is commonly supposed that classificatory kin relations represent "metaphorical extensions" of the "primary" relations of birth, if anything it is the other way around: birth is the metaphor' (2012: 677). What lies at the heart of both positions are 
metaphors. Metaphorical thought plays an important role in the concepts of kinship. As Sahlins notes, kinship is often perceived through shared substances of blood, milk, semen, flesh, bone, spirit (2011a, 2011b).

A metaphorical expression provides a relation between a source concept and its target concept, which is essentially based on analogy (Pinker 2007: 253-55). Metaphors are extensions from one semantic domain to another. As kinship is by definition relational, I propose here that perhaps the very concept of kinship is the model for metaphorical thinking. Metaphors, probably unique to our species, are fundamental for human cognition. They are produced when a concept from one domain (target source) is related to another concept from another domain (Kronenfeld 1996; Lakoff and Johnson 1980). George Lakoff asserts that metaphors are not mere linguistic expressions, but conceptual mappings that physically exist in the brain structure. According to Lakoff, the neural theory of metaphor explains the 'neural computational mechanisms' involved in their production (2009: 4).

Social cognition is fundamental for the functioning of human society, beginning with the recognition of one's immediate caregivers, usually one's kin or those who are perceived as kin. Concepts of kinship are often expressed metaphorically. I argue here that metaphorical thought might have originated at the same time as the need for social recognition that required charting and navigating the space of kin. I will draw on recent research in psychology and neurology that provide the psychological and biological underpinnings of metaphorical thought. Further, I will analyse ethnographic examples of kinship metaphors from the Mediterranean region, within the domain of plants and the domain of clothing, to show that these two semantic domains are members of a more inclusive class of 'coiling things' finding their way to the domain of kinship through the analogy of relations. This is also exemplified in visual metaphors associated with kinship that Carl Schuster collected from a broad range of societies from prehistoric to living ethnographic examples (Schuster and Carpenter 1996). Finally, I will hypothesise that thinking about kinship as primarily a system of relations might have been the model for thinking about the world. Indeed, we might say that thinking about kinship is the mother of all thought.

In Scheffler's approach, metaphoric extensions of kinship terms from focal kin terms to nonfocal ones play a fundamental role (Scheffler 1972; Scheffler and Lounsbury 1971). Following Lounsbury, Scheffler writes: 
[M] etaphor is often described as simile without the 'like', but we must consider the underlying semantic structure of such a comparison. It consists in suspending one or more of the defining features (criterial attributes) in the primary sense of the word and substituting in its place some feature of connotative meaning which is associated with the primary sense of the word. In the process connotative features become criterial. By this means words may be transferred from one semantic domain to another, for example from the domain of classification to the domain of classification on the basis of kinds of social or affective relationships (1972: 319).

Scheffler highlighted the very nature of metaphorical usage, namely metaphors necessarily only partially overlap with their referents' meanings. If the two sets of connotations were the same there would be no metaphor. For example, the American kinship term mother only in some of its criterial features corresponds to the criterial features of 'mother superior'. Although speakers might refer to the latter only as 'mother', they know she is only in some attributes like a biological mother. For Scheffler, the genealogical reference is primary and its many metaphoric extensions are secondary. Moreover, metaphors are not only a partial overlap of two concepts across semantic domains, but are based on the comparisons of relations between the concepts and other members within their respective domains, or between whole classes of objects and their relations.

\section{Social cognition and metaphors of space}

It has been suggested that our understanding and descriptions of the world are largely, and mostly unconsciously, structured by metaphors. Most conceptual metaphors are derived from human spatial orientation (Lakoff and Johnson 1980; Pinker 2007). Humans use concrete references to orientation in space to express the broad range of other more difficult and often abstract or ambiguous meanings. For example, up/down and in/out orientations supply metaphorical models for emotional states, such as in the expressions 'the mood was uplifting', 'it is all downhill after 40', and 'she is down and out on her luck'.

Giovanni Bennardo (2010) argues that the ability to think about space also allows for the observation of ideas as real objects from different perspectives. The conceptual use of space makes use of perspective-taking within a Frame of Reference (FOR). In the Basic FOR the viewer (speaker) is the central point from which she/he constructs the space within a set 
of three coordinates: sagittal, vertical and transversal. The Intrinsic FOR has at its centre another object separate from the viewer, and the Absolute FOR uses fixed orientation markers, such as cardinal points (2010: 382). In kinship systems this is evident in the position of ego as well as in the ability to put one's self in the position of alter. Orientation in space, as an ontological prime, is replicated in other domains, such as time, as well as kinship. Thus time is perceived as motion in the orientation space within a FOR and the concept of space is also used as a metaphorical referent to time (Lakoff and Johnson 1980; Pinker 2007). An example of time metaphorically expressed with a space referent comes from Croatian colloquial language when space is sometimes substituted with time prepositions, as in the expression ' $i z a$ rata', literally 'behind the war' instead of after the war.

Ethnographic examples of time-as-space come from the Inca view of time clearly rooted in FOR. The Inca culture contemplated the past and future in reverse to western cultures, so the past is in front because it can be seen, the future is behind because it is invisible. The head is also associated with the beginning and the source, while the feet with chaos and the dead (Classen 1993: 111-12). One of the most important Inca concepts was pachacuti, the reversal of space and time. The reforms of the great Inca ruler Pachacutec were considered to have been groundbreaking reversals, but the catastrophe of Spanish conquest of the Inca Empire was also referred to as pachacuti. Likewise, the millenarian myth of Inkarri foretells the return of the metonymic figure of the Inca king and the reversal, the pachacuti, to the old Inca ways. It is a concept associated with pacha, 'mother earth', and her spatial as well as temporal attributes (Allen 2002; Classen 1993).

Bennardo proposed that the use of different FOR perspectives, egocentred or alter-centred, generate kinship terminologies that focus on ego or other than ego (2010: 382). In English one's kin, as well as friends, are often referred to as 'close' or 'distant'. One of the most common spatial metaphors is the association between closeness and warmth derived from the close physical experience when in contact with other members of the social group, such as grooming, breast feeding or comforting a child, having sex, or just socialising (Ijzerman and Koole 2011). Research in developmental psychology shows the presence of spatial knowledge, as well as the ability to recognise faces in early infancy. Based on these findings the two seem connected-closeness/distance in physical space and known/unknown faces in social space. In other words, spatial orientation and social cognition are connected. According to 
social psychologists, communal sharing relationships that imply spatial proximity are grounded 'in innate and evolved mechanisms, or relational models that allow people to coordinate social interaction' (Fiske 1992: 701). This is conceptualised by crossing over from the domain of space to the domain of close kin as focal members and its extensions. To cite just a couple of ethnographic examples, among many kinship metaphors, when extended to nonrelatives, the brother metaphor suggests a horizontal egalitarian relationship such as in many 'brotherhoods' in the western tradition, while father/child indicates a hierarchical relationship (Rigney 2001). This confirms Mary Douglas's (1966) suggestion that the human body can stand for anything and vice versa, anything can stand for human body exemplified in English metaphors 'the head of state' and 'body politic' as well as in the Inca view quoted above where head is associated with life and order, and feet with death and chaos. The human body and its limbs can also represent kin-group segmentation, such as among some Bedouin groups (El Guindi 2010).

\section{Neurological underpinnings for metaphorical thought}

Although the exact underlying mechanisms involved in the production of metaphors are subject to current debates, metaphorical mappings involving neural pathways that cross various domains have been corroborated in neurological studies (Anderson 2010: 25). Metaphorical use from the domain of the bodily experiences, particularly the orientation in space, extends to referents in the social domain. How is this grounded in human neurology and the functioning of the brain? Lakoff studied the neural circuits involved in the production or understanding of metaphors:

During learning, much of the abstract domain is structured by fixed projections from the embodied domain. When processing source domain words in the context of a target domain subject matter, the fixed connections result in co-activation of the two domains. Thus, source domain activations arising from inferences are projected onto the target domain via the preestablished mapping (2009: 18).

Neurological research has shown that traumatic injuries to the left peri-Sylvan region result in the impairment of relational knowledge. Cognitive disorders following stroke and associated with autism and schizophrenia, among others, involve the inability to produce or understand 
metaphors. Cognition seems to be grounded in sensory-motor terms such as visual, gustatory, olfactory or tactile. For example, thinking about an object recalls a particular physical experience with that object simulating it in the brain (Pecher, Boot and Van Dantzig 2011:218). Metaphors based on different sensory-motor concepts may have different neural substrates. Metaphorical use of image schemata explain how abstract concepts can also be grounded in physical experience (Lakoff 2009; Pecher, Boot and Van Dantzig 2011: 219). Neuroimaging studies of the neural basis of metaphors show that conventional metaphors found in everyday language trigger the neural circuits in the right hemisphere, while unconventional ones, such as those found in poetry and literature, activate the left (Schmidt et al. 2010).

\section{Kinship metaphors}

A broadly defined metaphor is an extension of some attributes of the source term out of its domain to a target item in another domain (Kronenfeld 1996). Moreover, it is an applied analogy of relations (Pinker 2007). Research in psychology suggests that the conceptual metaphor is a unique cognitive mechanism that shapes social thought and attitudes (Landau, Meier and Kiefer 2010). As Scheffler has noted in his discussion of focality in kinship (1972), human kinship implies much more than primary kin recognition as well as genealogical relationships that might be real or fictional. It abounds with multiple symbolic meanings and metaphors that presuppose the cognitive abilities far beyond the capacity of nonhuman primates (Leaf and Read 2012; Milicic 2013). Understanding kinship through metaphors is common across cultures. Thus varied classification of kin often includes the denial of biological reproduction, as well as the metaphorical creation of kinship ties where there are none. However, that does not imply a lack of biological knowledge.

Scheffler's (1972) stance on metaphors, discussed above, has been amply corroborated by several authors (Shapiro 2012; Shapiro Chapter 1). According to Lakoff (1990), the English term mother is radially structured with respect to a number of its subcategories defined by a cluster of converging cognitive models - the birth model, the nurturance model, etc. In addition, there are 'noncentral extensions' such as birth mother, adoptive mother, surrogate mother, etc. that are variants acquired through learning. These latter terms are understood via their relationship to the central category of mother (ibid.: 91). The capacity for metaphorical thought 
implies partial overlap between two semantic domains (Kronenfeld 1996; Lakoff and Johnson 1980; Pinker 2007) and a 'blended space' (Lakoff 2009; Pecher, Boot and Van Dantzig 2011). Many cultures use metaphors of creeping plants such as 'grapevines' (Milicic 1998), or other winding objects, to think about kin groups. This metaphorical usage is based on image schemata-mental associations between two referents based on similarity and important for grounding abstract concepts (Lakoff 1990: 106). The relative similarity between the source and the target can be in shape (denotative), function (connotative), or based on the similarity of relation between the source and its larger framework (Kronenfeld 1996).

In the Croatian ethnographic example of the metaphoric use of grapevines in the domain of kinship the similarity is connotative: the kin group, referred to as a grapevine is based on what it does rather than what it is. In the village of B., located on the island of Hvar off the Croatian coast with about 150 permanent inhabitants, villagers are keenly aware of their kin ties as evidenced by frequent references and discussions about the membership in a particular kin group or loza (grapevine). If not entirely sure, they employ a kinship calculus tracing the relations, and relations of relations, to locate an individual mentally within the kin network. The most inclusive category of relatedness is the village itself in opposition to another village on the island, or the island in opposition to the entire mainland. When in need of favours the villagers refer to one another by the generic term zermo (relative). Within the village, individuals were most often identified at the level of the loza (grapevine) or kin group. A loza is a bilateral localised kin group with an apical ancestor, male or female, associated with a house. Its loza name is added to all individual names, since many have identical first and last names (Milicic 1998). There are about 15 'grapevines' with living members. Many of these individual 'grapevines' are actually branches of the same 'grapevine' that got detached from its 'stem' in some more or less distant past. Some of these original connections are forgotten, but many are remembered and often commented upon. The ideal of village endogamy and socioeconomic homogamy necessarily presented problems and overlapping of lozas, which was partially solved by splintering off.

In the denotative sense of what it $i s$, a grapevine is a plant, while in the connotative sense, to what it does, it is a winding, coiling, creeping thing. An object not in the domain of plants, but with similar attributes, is the zinari, a long winding belt in Greek folk costume, also metaphorically used when thinking about kinship. It is wrapped several times around 
the waist, and it metaphorically represents degrees of blood relatedness. In the Greek folk model the contrasting metaphors of blood and oil refer to consanguineal and spiritual kinship respectively, the latter established through baptism as an extension of the degrees of blood kinship (du Boulay 1984; Just 2000). In the Pidhalion, the Greek Orthodox Church instructions, the first permissible marriage is between third cousins. In the local interpretation, it is permissible between ego and the child of a third cousin. In contrast, marriage is forbidden between affinal (in-law) kin of the relatives of prohibited degrees down to and including the sixth degree (ibid.: 101). The number of turns of the metaphorical belt explicitly describes the genealogical distance as an index of prohibited degrees of marriage. The zinari represents the winding path of blood that must always be directed in the same direction. 'The blood must not turn around' lest an act of incest is committed (du Boulay 1984: 548). Similarly, god parenthood, or ritual sponsorship, is always asymmetrical and collective because it binds not just individuals but two families who cannot sponsor each other's children. The oil, used in the ritual of baptism is the symbol of god parenthood and the spiritual counterpart of blood and kinship: 'the oil and the blood must not turn around' (Just 2000: 131-35). God parenthood, or fictive kinship, as a collective notion is practised asymmetrically in that ritual sponsorship cannot be directly exchanged between two families. It is an explicit comparison of the rules of marriage that should not take place between those families who are already in-laws. Marriage and blood kinship between relatives within the prohibited degrees are considered incestuous, as well as direct symmetrical exchange of spouses such as two brothers marrying each other's sisters. It is an extension of consanguinity to the prohibition of reciprocal god parenthood, itself being a kind of parenthood.

In order to show that a metaphor is structured by our experience, Lakoff (1987: 276) asks three questions: (1) What determines the choice of a possible well-structured source domain? (2) What determines the pairing of the source domain with the target domain? (3) What determines the details of the source-to-target mapping? To follow him:

- The blood is a life-giving substance.

- The oil gives spiritual life in the ritual of baptism.

- The grapevine is an easily observable model of a fast-reproducing form of life in the environment.

- Kin relationships are similar to the winding grapevine shoots as evidenced in the metaphorical use of loza. 
- Kin space is envisioned as the space often 'invaded' by the everexpanding vines. Grapes are children to the grapevines.

- Kinship groups split when too large.

- Grapevine cuttings are used to plant new plants.

- New families that split off build new houses.

- New grapevines get new nicknames and old connections are broken.

Compared with the Greek example, we can see how both objects, one from the domain of plants, the other from the domain of clothing, are similar and comparable in terms of some of their attributes. The grapevine and the zinari kinship metaphors show how the two classes, plants and clothing, are merged into the same more inclusive class of 'coiling things' based on their shared winding, coiling image (Figure 34).

\begin{tabular}{|lr|}
\hline COILING THINGS & (image schema) \\
SHARED FUNCTION & LIQUIDS \\
Connotative & SHARED SUBSTANCE \\
(what something DOES) & Denotative \\
GRAPEVINES (Domain of plants) & (what something IS) \\
ZINARI BELT (Domain of clothing) & BLOOD (biological)/OIL (spiritual kin) \\
\hline
\end{tabular}

Figure 34. Image schema of the domain of plants and the domain of clothing

Source: (C) Bojka Milicic.

Just as the coiling grapevine metaphor facilitates the understanding of kinship dynamics in the first case, the Greek example provides insight into the character of kinship through the attributes of the long and winding zinari belt. In the latter example the analogy is between the domain of 'blood' kin and fictive kin metaphorically associated with the domain of another liquid substance-the oil establishing a spiritual relation and modelled on the concrete physical relation of 'shared blood'. The degrees of kin distance/closeness is perceived in terms of the clothing domain, the zinari belt, referring to it both denotatively (what the zinari IS) and connotatively (what the zinari DOES), coiling around the waist in one prescribed direction. But this is not all. This particular element of clothing is also analogous to the blood that 'must not return' in the rules of marriage. Hence reference to an item that coils around the body only in one direction also alludes to the ritual oil as the metaphor of spiritual kinship that also must not return lest an act of spiritual incest be committed. 


\section{Visual metaphors of kinship}

Carl Schuster (Schuster and Carpenter 1996) has compiled a collection of artefacts from numerous world cultures that depict various representations of kinship, from simple notches to elaborate figurative and abstract patterns in a broad range of media: clay, cloth, wood, and textiles. Etched, painted, carved, or woven objects and tattooed bodies carry motifs that represent ancestors expanding vertically or horizontally, and sometimes in both directions. Although it is hard to establish such meanings based on the archaeological record, many of the ethnographic examples in this work are explicitly associated with kinship, such as the motifs that repetitively evoke concatenation of stylised or realistically depicted human bodies. Alfred Gell (1993) has discussed numerous ethnographic examples of Polynesian tattooing patterns in the context of social structure and kinship. Thus in the Marquesas, the common tattoo motif of climbing, vine-like stylised human figures represents the etua (ancestors). Gell noted that one of the main attributes of Polynesian tattooing is its protective function of creating a second layer of skin, particularly in the use of the images of shell animals such as the tortoise. He also interprets the widely used Polynesian mythological motif of doubles in terms of its protective attributes. A Samoan tattoo pattern of the pe'a, the flying fox, illustrates the metaphorical connection between the domain of animals and the domain of kinship. The flying fox, a species of bat, hanging upside down envelops itself into its own wings creating a self-protective layer. The pe'a motif also occurs carved in the rafters and beams of a house that itself is a spatial and temporal representation of a kin group (ibid.: 96-99). Furthermore, Gell cites numerous examples of other Polynesian cultural practices, from many layers of tapa cloth to layers of fat, in terms of their protective functions metaphorically associated with kin groups as protective social layers (ibid.: 177-79).

The foregoing, very short selection out of numerous visual and verbal examples of kinship metaphors, shows the attributes of kinship expressed across the cognitive domains in terms of winding, coiling, layering or protective properties of various objects, as well as the analogy of relations and relations of relations within and between classes of objects. This makes plausible the hypothesis that metaphorical thought, fundamental to human cognition, at least originated simultaneously with or perhaps developed out of the social cognition and its fundamental field of kinship. 


\section{Possible origin of metaphorical thought}

How were metaphors produced in proto-human language and is it possible to hypothesise about an actual shift from the premetaphorical stage to the metaphor production stage? Steven Mithen (1996) has hypothesised that cognitive fluidity took place about 50,000 years ago through the opening of the connections between specialised cognitive modules and general intelligence, triggered by language bridging across the specialised cognitive modules. Using a metaphor from medieval sacral architecture, Mithen illustrates the architecture of the mind. In this model, language 'vandalised' the partitions between previously walled-off 'chapels', or modules, of social, natural and technical intelligence making possible the free flow of information between the four domains of intuitive knowledge (Figure 35 ). Thus, 'the mind acquires not only the ability but a positive passion for metaphor or analogy' (ibid.: 71). Of course, his theory is itself a metaphor: a concept or a set of ideas used to elucidate a more difficult concept or set of ideas across, in this case, the domains of sacral and cognitive architecture respectively.
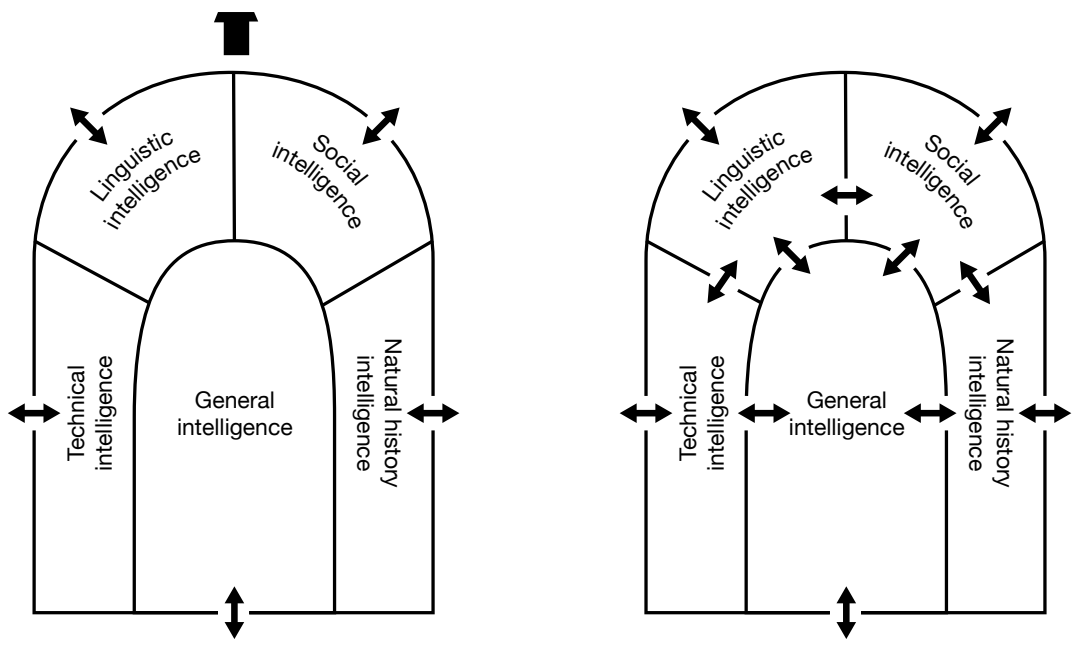

Figure 35. The mind as a chapel

Source: Adapted from Mithen (1996: 67) and used with the permission of $\odot$ Steven Mithen and Thames and Hudson Ltd. 
Mithen associates the transition itself with fully modern behaviour, the set of traits distinguishing our species from its predecessors as well as other primates, which is inferred from the archaeological record. There is a debate whether this transition actually took place as an abrupt behavioural change 40,000-50,000 years ago or more plausibly, considering the scale of changes, it evolved slowly over a longer period (Klein 2000). In a different approach, Murray Leaf and Dwight Read (2012) hypothesise the coevolution of thought and social organisation as evidenced in the archaeological record in the European Upper Paleolithic cave paintings within their new paradigm in the study of kinship. In this analysis the representations of various animals grouped together according to their respective species may be interpreted as the human capacity to understand the concept of class versus an individual as well as several more inclusive classes of classes. This is analogous to the ability to think about the individual selves, as well as classes of people and relations among them (ibid.: 68-88). I contend, then, that this is also the evidence of metaphorical thought founded not only on the similarity of objects, but on the analogy of relations within and between classes of objects. Concepts of kinship are the prime example of such thought associated with human behavioural modernity.

\section{Conclusion}

As Scheffler has proposed in his approach to kinship terminology, metaphorical thought is based not only on the similarity of objects, but also on analogical similarity of relation. This is one of the hallmarks of human cognition, but it is also the main attribute of kinship. I hypothesised here that concrete bodily experiences, rooted in the FOR and closely related to social cognition, triggered the metaphorical thought that was then used in other semantic domains. This is evident in the widespread metaphors of space that are used as concrete referents to the domain of kinship in terms of close/distant and transferred to the domain of emotions. The ethnographic examples of the referents across the domain of plants to the domain of kinship, as well as the metaphorical construction of fictive kinship, confirm that metaphorical thought is at the basis of human complex social cognition. The transition to cognitive fluidity between different semantic domains, probably fully in place by $40,000-50,000$ years ago, perhaps included kinship terminologies providing cognitive building blocks for the linguistic production of metaphors. 


\section{References}

Allen, Catherine. 2002. The Hold Life has: Coca and Cultural Identity in an Andean Community. Washington: Smithsonian Institution Press.

Anderson, Michael L. 2010. 'Neural reuse: A fundamental organizational principle of the brain'. Behavioral and Brain Sciences 33(4): 245-313. doi.org/10.1017/S0140525X10000853

Bennardo, Giovanni. 2010. 'Space, kinship, and mind'. Behavioral and Brain Sciences 33(5): 382-83. doi.org/10.1017/S0140525X10001925

Classen, Constance. 1993. Inca Cosmology and the Human Body. Salt Lake City: University of Utah Press.

Douglas, Mary. 1966. Purity and Danger: An Analysis of Concepts of Pollution and Taboo. London: Routledge \& Kegan Paul. doi.org/ $10.4324 / 9780203361832$

du Boulay, Juliet. 1984. 'The blood: Symbolic relationship between descent, marriage, spiritual prohibitions, and fictive kinship in Greece'. Man (n.s.) 19(4): 533-56. doi.org/10.2307/2802325

El Guindi, Fadwa. 2010. 'The cognitive path through kinship'. Behavioral and Brain Sciences 33(5): 384-85. doi.org/10.1017/ S0140525X10002050

Fiske, Alan P. 1992. 'The four elementary forms of sociality: Framework for a unified theory of social relations'. Psychological Review 99(4): 689-723. doi.org/10.1037/0033-295X.99.4.689

Gell, Alfred. 1993. Wrapping in Images: Tattooing in Polynesia. Oxford: Clarendon.

Ijzerman, Hans and Sander L. Koole. 2011. 'From perceptual rags to metaphoric riches-bodily, social, and cultural constraints on sociocognitive metaphors: Comment on Landau, Meier, and Keefer (2010)'. Psychological Bulletin 137(2): 355-61. doi.org/10.1037/ a0022373

Jones, Doug. 2010. 'Human kinship, from conceptual structure to grammar'. Behavioral and Brain Sciences 33(5): 367-416. doi.org/ 10.1017/S0140525X10000890 
Just, Roger 2000. A Greek Island Cosmos: Kinship \& Community on Meganisi. Santa Fe and Oxford: SAR Press.

Klein, Richard G. 2000. 'Archaeology and the evolution of human behavior'. Evolutionary Anthropology 9(1): 17-35. doi.org/10.1002/ (SICI) 1520-6505(2000)9:1<17::AID-EVAN3>3.0.CO;2-A

Kronenfeld, David B. 1996. Plastic Glasses and Church Fathers: Semantic Extensions from the Ethnoscience Tradition. New York: Oxford University Press.

Lakoff, George. 1987. Women, Fire, and Dangerous Things. Chicago: Chicago University Press. doi.org/10.7208/chicago/ 9780226471013.001.0001

- 2009. 'The neural theory of metaphor'. Social Science Research Network. doi.org/10.2139/ssrn.1437794

Lakoff, George and Mark Johnson. 1980. Metaphors We Live By. Chicago: Chicago University Press.

Landau, Mark J., Brian Meier and Lucas Kiefer. 2010. 'A metaphor enriched social cognition'. Psychological Bulletin 136(6): 1045-67. doi.org/10.1037/a0020970

Leaf, Murray J. and Dwight Read. 2012. The Conceptual Foundation of Human Society and Thought: Anthropology on a New Plane. Lanham, MD: Lexington Books.

Milicic, Bojka. 1998. 'The grapevine forest: Kinship, status, and wealth in a Mediterranean community (selo, Croatia)'. In Kinship, Networks, and Exchange, edited by Thomas Schweizer and Douglas R. White, 15-35. Cambridge: Cambridge University Press. doi.org/10.1017/ CBO9780511896620.004

- 2013. 'Talk is not cheap: Kinship Terminologies and the Origins of Language'. Structure and Dynamics: e-Journal of Anthropological and Related Sciences. Online: escholarship.org/uc/item/6zw317jh (accessed 1 June 2017).

Mithen, Steven. 1996. The Prehistory of the Mind: The Cognitive Origins of Art, Religion, and Science. London: Thames and Hudson. 
Pecher, Diane, Inge Boot and Saskia Van Dantzig. 2011. 'Abstract concepts: Sensory-motor grounding, metaphors, and beyond'. In The Psychology of Learning and Motivation, edited by Brian Ross, 217-48. Burlington: Academic Press. doi.org/10.1016/b978-0-12385527-5.00007-3

Pinker, Steven. 2007. The Stuff of Thought: Language as a Window into Human Nature. New York: Viking.

Rigney, Daniel. 2001. The Metaphorical Society: An Invitation to Social Theory. Lanham, MD: Rowman and Littlefield.

Ross, Brian (ed.). 2011. The Psychology of Learning and Motivation. Burlington: Academic Press.

Sahlins, Marshall. 2011a. 'What kinship is (part one)'. Journal of the Royal Anthropological Institute (n.s.) 17(1): 2-19. doi.org/10.1111/j.14679655.2010.01666.x

- 2011b. 'What kinship is (part two)'. Journal of the Royal Anthropological Institute (n.s.) 17(2): 227-42. doi.org/10.1111/j.14679655.2011.01677.x

—_. 2012. 'Birth is the metaphor. Comment'. Journal of the Royal Anthropological Institute (n.s.) 18(3): 673-77. doi.org/10.1111/j.14679655.2012.01782.x

Scheffler, Harold W. 1970. 'The Elementary Structures of Kinship, by Claude Lévi-Strauss: A review article'. American Anthropologist 72: 251-68. doi.org/10.1525/aa.1970.72.2.02a00020

- _. 1972. 'Kinship semantics'. Annual Reviews in Anthropology 1: 309-28. doi.org/10.1146/annurev.an.01.100172.005121

Scheffler, Harold W. and Floyd Glenn Lounsbury. 1971. A Study in Structural Semantics: The Siriono Kinship System. Englewood Cliffs, NJ: Prentice Hall.

Schmidt, Gwenda L., Alexander Kranjec, Eileen R. Cardillo and Anjan Chatterjee. 2010. 'Beyond laterality: A critical assessment of research on the neural basis of metaphor'. Journal of the International Neuropsychological Society 16(1): 1-5. doi.org/10.1017/ S1355617709990543 
FOCALITY AND EXTENSION IN KINSHIP

Schuster, Carl and Edmund Snow Carpenter. 1996. Patterns that Connect: Social Symbolism in Ancient and Tribal Art. New York: Harry N. Abrams.

Schweizer, Thomas and Douglas R. White (eds). 1998. Kinship, Networks, and Exchange. Cambridge: Cambridge University Press. doi. org/10.1017/CBO9780511896620

Shapiro, Warren. 2012. 'Extensionism and the nature of kinship. Comment'. Journal of the Royal Anthropological Institute (n.s.) 18(1): 191-93. doi.org/10.1111/j.1467-9655.2011.01738.x 
This text is taken from Focality and Extension in Kinship: Essays in Memory of Harold W. Scheffler, edited by Warren Shapiro, published 2018 by ANU Press, The Australian National University, Canberra, Australia.

doi.org/10.22459/FEK.04.2018.10 